\title{
EL CONCEPTO DE SOCIEDAD EN ANTROPOLOGÍA ${ }^{1}$
}

Eduardo Viveiros de Castro ${ }^{2}$

\section{Los dos sentidos}

En sentido general, la sociedad es una condición universal de la vida humana. Esta universalidad admite una interpretación biológica (instintiva) y otra simbólico-moral (institucional). Por un lado, la sociedad puede ser vista como un atributo básico, pero no exclusivo, de la naturaleza humana: estamos genéticamente predispuestos a la vida social; la ontogénesis somática y de comportamiento de los humanos depende de la interacción con sus semejantes, la filogénesis de nuestra especie es paralela al desarrollo del lenguaje y del trabajo, capacidades sociales indispensables para la satisfacción de las necesidades del organismo. Por otro lado, la sociedad puede ser vista como dimensión constitutiva y exclusiva de la naturaleza humana (Ingold, 1994), definiéndose por su carácter normativo: el comportamiento humano se convierte en agencia social al fundarse menos en regulaciones instintivas seleccionadas por la evolución que en reglas de origen extrasomático históricamente sedimentadas.

La noción de "regla" puede ser tomada en sentido moral y prescriptivo-regulativo (como en el estructural-funcionalismo) o cognitivo y descriptivo- constitutivo (como en el estructuralismo y la antropología simbólica); a pesar de esta importante

\footnotetext{
1 Este texto fue encargado y publicado por la Encyclopedia of Social and Cultural Antrophology, organizada por A. Bernard \& J. Spencer. Sus limitaciones de contenido, estilo y dimensiones (de bibliografía incluso) reflejan tal origen. Este no pretende ser más que un mapa muy general de las incidencias del concepto de sociedad en la disciplina antropológica. 2 La presente traducción se ha realizado de la versión en portugués del capítulo 5 (Conceito de sociedade em antropología) del libro $A$ inconstância da alma selvagem e outros ensaios de antropologia. São Paulo: Cosac \& Naify, 2002. Traducido por Diana Rodríguez Vértiz.
} 
diferencia, en ambos casos el énfasis en las reglas exprime el carácter instituido de los principios de acción y de organización social. Los contenidos normativos de la sociedad humana, siendo realidades institucionales, varían en el tiempo y en el espacio, pero la existencia de reglas es una invariante formal (Lévi-Strauss 1967ª Fortes 1983); como tal, esta sería la característica distintiva de la condición social, que deja aquí de ser uno de los atributos del homo sapiens para definir la humanidad como entidad singular, ya no compuesta por individuos sino por sujetos que son simultáneamente creadores y criaturas del mundo de las reglas.

En sentido particular (una sociedad) es una designación aplicable a un grupo humano con algunas de las siguientes propiedades: territorialidad, reclutamiento principalmente por reproducción sexual de sus miembros; organización institucional relativamente autosuficiente y capaz de persistir después del periodo de vida de un individuo; distintividad cultural.

Aquí la noción puede tener como referentes principales el comportamiento poblacional o componente institucional-relacional, o el componente cultural-ideacional el grupo (Firht 1951). En el primer caso, el término es usado como sinónimo de "(un) pueblo" visto como un tipo específico de humanidad. En el segundo, que es equivalente a "sistema" u "organización" social, se destaca el cuadro sociopolítico de la colectividad: su morfología (composición, distribución y relaciones de los subgrupos de la sociedad en cuanto grupo máximo), el cuerpo de normas jurídicas (nociones de autoridad y ciudadanía regulación de conflictos, sistemas de status y de papeles) y las configuraciones características de las relaciones sociales (relaciones de poder, formas de cooperación, modos de intercambio). En el tercer caso - en el que sociedad es frecuentemente sustituida por "cultura" - se miran los contenidos afectivos y cognitivos de la vida del grupo: el conjunto de disposiciones y capacidades inculcadas a sus miembros a través de medios simbólicos variados, como conceptos y prácticas que confieren orden, significación y valor a la totalidad de lo existente.

Una de las formas de administrar la relación entre los dos sentidos de "sociedad" fue por la división de la antropología en un aspecto etnográfico o descriptivointerpretativo, virado hacia el análisis de lo particular y privilegiando las diferencias entre las sociedades; y un aspecto teórico o comparativo-explicativo, que procura formular proposiciones sintéticas válidas para toda sociedad humana. A pesar de las tentativas de definirlos como etapas metodológicamente complementarias, la tendencia histórica ha sido la de una polarización epistemológica entre "etnografía" y "teoría”. La perspectiva universalista predominó en la fase formativa de la antropología, con énfasis en el método comparativo y en la definición de grandes tipos de sociedad; en seguida, el culturalismo y el funcionalismo marcaron el periodo áureo del método etnográfico, usado polémicamente para la demolición de tipologías especulativas (Boas) o como vía de acceso directo a lo universal (Malinowsky); los estructuralismos de Radcliffe-Brown y Lévi-Strauss y los neoevolucionismos americanos (L. White, J. Steward), por su parte, volvieron a mirar hacia la comparación y la generalización.

A partir de los años 60 esa divergencia se hace más profunda. De un lado el interés por el significado y la interpretación reubicó a la etnografía como dimensión privilegiada, valorizando el punto de vista de los agentes y buscando en las 
diferentes "etnoconcepciones" de sociedad una perspectiva que relativizara críticamente los conceptos del observador. La sociedad en un sentido general se subordina a la sociedad en un sentido particular o plural. Más que eso, en la medida en la que las concepciones culturalmente específicas de sociedad desafían la atribución de un valor referencial fijo de esta noción, esta pasa a ser aprehensible apenas a través de la(s) cultura(s), y, en el límite, a existir meramente como uno de sus contenidos. Por otro lado, el desarrollo de la sociobiología, la psicología cognitiva y de la ecología cultural han conducido a hipótesis ambiciosas sobre la sociedad en cuanto propiedad genética de la especie, proponiendo universales de comportamiento y cognitivos (y remitiendo eventualmente la diversidad fenotípica del etnograma humano a variables extrínsecas, como el ambiente). Tal polarización entre interpretaciones culturalistas y explicaciones naturalistas terminó por vaciar el concepto de sociedad, el cual se vio reducido a la representación particular, o al comportamiento universal.

\section{Las dos concepciones}

El pensamiento occidental oscila entre dos imágenes de sociedad, opuestas y combinadas de modo históricamente variable, donde se funden los sentidos particular y general de esta noción. Podemos llamarlas, como Dumont (1965), de societas e universitas, o, usando la distinción difundida por este mismo autor, de concepciones "individualista" y "holista" de lo social. La primera se funda en la idea de contrato entre átomos individuales ontológicamente independientes: la sociedad es un artificio resultante de la adhesión consensual de los individuos, guiados racionalmente por el interés, a un conjunto de normas convencionales, la vida social está en discontinuidad radical con un estado de naturaleza, que niega y trasciende. De inspiración universalista y formalista, esta concepción tiene como modelo metafórico (y generalmente causa final) el Estado constitucional y territorial, y como problema típico los fundamentos de orden político. La segunda se funda en la idea de un todo orgánico preexistente empírica o moralmente en sus miembros, de este emanan y retiran su substancia: la sociedad es una unidad corpórea orientada por un valor trascendente, es un universal concreto donde la naturaleza humana se realiza. De inspiración particularista y sustantivista, su modelo metafórico (y algunas veces causa eficiente) es el parentesco como principio natural de construcción de personas morales colectivas, y su problema típico es el de la integración cultural de un pueblo en cuanto Nación. Las grandes imágenes modernas para estas concepciones son respectivamente el contrato (o su negativo, el conflicto) y el organismo, que atraviesan la antropología del siglo xx sobre avatares múltiples, entre los cuales uno de los más conspicuos fue el contraste entre "teorías de acción” y “teorías de la estructura” ( Giddens, 1979, 1984; Verdon 1991).

La universitas está asociada a un horizonte premoderno dominado por el pensamiento de Aristóteles; la societas a los teóricos del jusnaturalismo, de Hobes a Hegel (Bobbio 1993). Se debe recordar que la antigüedad conoció sociologías artificialistas como los sofistas y Antístenes, y que el nominalismo medieval preparó el terreno para las teorías modernas del contrato. Por su parte el modelo holístico y organicista 
de la universitas resurgió en la reacción romántica al Iluminismo, desempeñando un papel fundamental en el desarrollo de la imagen antropológica de (una) sociedad como una comunidad étnica de origen que comparte un mundo de significados tradicionales legitimados por la religión. Por otro lado, buena parte de la antropología victoriana y su descendencia puede ser vista como heredera tardía del Iluminismo (Stocking 1987).

Una de las manifestaciones de la polaridad societas/universitas es la concurrencia entre "sociedad" y "cultura" como rótulos englobantes para el objeto de la antropología, que opuso las dos tradiciones teóricas dominantes entre 1920 y 1960 . La noción de sociedad, característica de la "antropología social" británica, deriva de la sociedad civil de los jusnaturalistas, del racionalismo francés y escocés del siglo XVIII y, más próximamente de las sociologías de Comte, Spencer y Durkheim. La noción de cultura, emblema de la "antropología cultural" americana, tiene raíces en el Romanticismo alemán, en las escuelas histórico-etnológicas de la primera mitad del siglo XIX, y directamente en la obra de Boas. Esto no significa que se pueda derivar unívocamente la antropología social del individualismo de las societas y la antropología cultural del holismo de la universitas. Sobre ciertos aspectos, las cosas se pasan al inverso. Maine o Durkheim, por ejemplo, al mismo tiempo que asimilaron los esquemas progresistas del siglo XVIII, reaccionaron ante el artificialismo y utilitarismo asociados a estos, en nombre de concepciones esencialistas y organicistas que inspirarían la antropología de Radcliff-Brown y sus seguidores. Por su parte, Boas, heredero del idealismo y del historicismo alemán, tendrá una concepción nominalista de la cultura, concibiendo al individuo como único locus real de la integración cultural. Pero no hay duda de que se encuentran marcas del utilitarismo racionalista en varias tendencias de la antropología social, particularmente en el funcionalismo de Malinowski o Leach y en el componente spenceriano del pensamiento de Radcliffe-Brown; es igualmente claro que las preocupaciones "configuracionales" de los antropólogos americanos como Kroeber, Benedict o Geertz derivan del paradigma romántico de la sociedad como organismo espiritual.

\section{Las dos antinomias}

Sociedad y cultura vinieron a dividir todavía el campo estructurado por la oposición jusnaturalista entre "(estado de) naturaleza" y "sociedad (civil)", con la diferenciación de las dos antinomias centrales de las ciencias humanas: naturaleza/ cultura e individuo/ sociedad. Ambas connotan el mismo dilema teórico, el de decidir si las relaciones entre los términos opuestos son de continuidad (solución reduccionista) o de discontinuidad (solución autonomista o emergente). ¿La cultura es un prolongamiento de la naturaleza humana, exhaustivamente analizable en términos de la biología de la especie, o es un orden suprabiológico que ultrapasa dialécticamente su substrato orgánico? ¿La sociedad es la suma de las interacciones y representaciones de los individuos que las componen, o es su condición supraindividual, y como tal es un "nivel" específico de la realidad? 
Los cruzamientos de las dos polaridades son complejos, pues estarían frecuentemente subsumidas una en la otra, con "sociedad" o "cultura" oponiéndose a "individuo" y "naturaleza" las dos últimas nociones son bastamente polisémicas. "Individuo" posee un sentido empírico universal (los ejemplares individuales de la especie, el componente humano de cualquier sociedad) y un sentido cultural particular (el individuo como valor último, origen y finalidad de las instituciones sociales). "Naturaleza", por su parte, puede significar el mundo físico material en oposición a las representaciones simbólico-conceptuales, el dominio de los hechos versus el dominio de los valores, el componente innato o constante del comportamiento humano en oposición a su componente adquirido o variable, o espontáneo y necesario versus lo artificial y convencional, la animalidad en oposición a la humanidad, y así en adelante.

La idea de que lo social-cultural está "encima" de lo individual y/o natural aparece en todos los autores que definieron las grandes orientaciones de la antropología, pero con diferencias importantes (Ingold 1986). Spencer concibe la sociedad como resultado de la asociación interactiva de los individuos y como instrumento de los fines de estos últimos; esta constituye una esfera supraindividual, pero no suprabiológica, de la realidad. La sociedad es un fenómeno natural (que no distingue a los hombres de otros animales), siendo la fase superogánica de un proceso evolutivo universal que engloba las esferas inorgánica y orgánica. Durkheim se sitúa en el extremo opuesto, viendo la sociedad como un fenómeno exclusivamente humano, una realidad supraindividual y suprabiológica sui generis, de naturaleza moral y simbólica.

Esta es una totalidad irreductible a sus partes, dotada de finalidad propia, una conciencia colectiva superior y exterior a las conciencias individuales producida por la fusión de estas últimas. Con Boas, en fin, la antonimia recibe una tercera solución: la cultura es una realidad extrasomática de tipo ideacional, pero no constituye un dominio ontológico distinto; existiendo en las mentes individuales, es individual y suprabiológica, una entidad nominal (semejante a la especie darwiniana) reductible a los comportamientos adquiridos; y la sociedad es el instrumento de transmisión de la cultura entre los individuos.

Las teorías antropológicas posteriores exhiben combinaciones de estos tres paradigmas. La teoría cultural de Kroeber, por ejemplo, osciló entre posiciones boasianas y durkhemianas aunque su concepto de sociedad es de tipo spencieriano. En general, la antropología americana tendió a concentrarse en el par cultura/naturaleza, tomando el segundo concepto ora en el sentido de naturaleza humana —analizando entonces los patrones afectivos y cognitivos de los individuos por la cultura, o al contrario, buscando establecer constantes psicológicas transculturales-, ora en el sentido de naturaleza no humana como en el caso de las tendencias llamadas materialistas, que conciben la cultura como instrumento y resultado de un proceso de adaptación al ambiente.

La antropología social británica, en cambio, orientó su eje problemático en la polaridad individo/sociedad y en los conceptos (heredados del organicismo) que la expresaban: "estructura" y "función". Para Malinowski, el concepto de función se refería al papel desempeñado por las instituciones sociales en la satisfacción de las necesidades básicas de los organismos individuales. Para Radcliffe-Brown designaba 
la contribución de estas instituciones en la manutención de las condiciones de existencia del organismo colectivo, definición que responde al problema central de la teoría estructural-funcionalista, los dos fundamentos y modos de permanencia de una forma social dada. Sobre el nombre de "reproducción", el problema no fue menos central para el marxismo antropológico difundido a partir de los años 70, el cual puede ser considerado como una variante tardía del estructural-funcionalismo.

Radcliffe-Brown desarrolló tanto definiciones natural-interactivas como moral-regulativas del concepto de estructura social, vacilando entre la imagen de una red de relaciones interindividuales y la de una orden normativa de relaciones de intergrupos. La imagen preponderante, entre tanto, fue la de una estructura como codex “jural" que ubica personalidades sociales con individuos o colectividades, definiendo su posición relativa en términos de derechos y deberes. Esta concepción, profundizada sobre todo por Fortes, conoció su época de hegemonía. Pero la orientación individualista y utilitarista, que tuvo en Malinowski a su gran campeón antropológico, comenzó a volver a primer plano con la reacción de Leach al estructural-funcionalismo, y en seguida floreció en diversas alternativas transnacionales al paradigma durkhemiano, todas insistiendo en la diferencia entre código normativo y organización empírica, la sociedad oficial y la sociedad real, y privilegiando las "estrategias" o el "proceso" contra las "normas" o la "estructura", la "acción" contra la "representación" y el "poder" contra el "orden". Estos contrarios conceptuales manifiestan el dilema clásico de la antropología británica, la disyunción entre las "normas" y la "práctica", que por su parte traduce la persistencia de la antinomia sociedad/individuo en esta tradición teórica.

Lévi-Strauss, por su parte, heredó de los boassianos la cuestión de la relación entre universales psicológicos y determinismos culturales, el interés por la dimensión inconsciente de los fenómenos sociales, y el lenguaje de la oposición naturaleza/ cultura. Aunque su tratamiento de esta última oposición evoca las tentativas clásicas de proporcionar una génesis ideal de la sociedad a partir del estado de naturaleza, y su "cultura" guarda muchas analogías con la noción de sociedad civil. Al definir la prohibición del incesto y del intercambio matrimonial como condición trascendental de la sociedad humana, el autor concibe el pasaje entre las órdenes de la naturaleza y de la cultura en términos sociopolíticos directamente inspirados en la teoría de la reciprocidad de Mauss, teoría que ya fue leída como respuesta alternativa el problema hobbesiano de la emergencia del orden social a partir del estado natural de guerra, con el Don y el cambio puestos como el análogo primitivo del Estado y del contrato (Sahlins 1972). Pero Lévi-Strauss también tomará a Boas y a Sassure para explorar un nuevo modelo analógico para los modelos culturales, el lenguaje. Al contraponer a la tesis durkhemiana sobre los orígenes sociales del simbolismo el tema de los fundamentos simbólicos de lo social, va a derivar tanto la cultura como la sociedad del mismo sustrato, el "inconsciente", lugar donde se anularán las antinomias naturale$\mathrm{za} /$ cultura e individuo/sociedad.

El modelo del lenguaje subyace a la condición lévi-straussiana de estructura como código, esto es, a un sistema de signos dotados de valores posicionales. El problema organicista de la función da aquí lugar al problema semiótico del sentido, 
desplazamiento que, entre otras cosas, responde a la poca importancia concedida por el estructuralismo a la noción de estructura social. Aparte de su libro sobre parentesco donde todavía se hayan empleos de "estructura" próximos a los significados tradicionales, Lévi-Strauss se concentró en complejos clasificatorios y mitológicos, esto es, en estructuras más propiamente "culturales". Al proclamar, en un famoso texto, que la etnología era una psicología, el antropólogo francés terminó de disolver la distinción entre sociedad y cultura; con esto, el estructuralismo contribuyó indirectamente para el dominio actual del concepto de cultura sobre el de sociedad en la escena antropológica. Este mismo énfasis en los aspectos taxonómicos y cognitivos de la vida social ha sido señalada, en las evaluaciones contemporáneas, como síntoma de una de las limitaciones mayores del estructuralismo: su dificultad en dar cuenta del pasaje entre significación y acción, los órdenes concebidos y los órdenes vividos, la estructura y la historia. Este diagnóstico llevó a la antropología contemporánea a experimentar una variedad de nuevos abordajes, en general adjetivados como "fenomenológicos".

\section{Las dos sociedades}

Los problemas asociados a la noción de sociedad en sentido particular tienen relación, principalmente, con el establecimiento de tipos históricos y morfológicos, y los principios de relación entre estos.

La distinción entre tipos sociales tiene una larga historia intelectual. Un esquema especialmente influyente fue la tripartición iluminista entre pueblos salvajes, bárbaros y civilizados, de carácter inicialmente más geográfico que histórico (Montesquieu, por ejemplo) la cual fue temporalizada principalmente pensadores como Turgot, Adam Smith, Ferguson y Condorcet, generando después la ley de los tres estadios de Comte, de gran importancia para las teorías victorianas de la religión (Stocking 1987). Este esquema ganó ciudadanía antropológica plena con la división de Morgan en sociedades de cazadores-recolectores (salvajería), sociedades agrícolas (barbarismo) y sociedades industriales o complejas (civilización), que fue incorporada por el pensamiento marxista y desarrollada por las teorías neoevolucionistas (Earle 1994). Las tipologías tripartitas son en general continuistas y nomotéticas, buscando principios y mecanismos de pasaje de un estado a otro.

El esquema de mayor productividad en el pensamiento occidental, mientras tanto, fue el dicotómico, que se presta mejor para discontinuidades fuertes. Traduciendo la polaridad conceptual entre universitas y societas en términos de una oposición real, las dicotomías tipológicas destacan aspectos variados de un contraste en última instancia reductible a "Nosotros" versus los "Otros", constituyendo el núcleo de teorías del Gran Divisor que singularizan a Occidente moderno frente a las demás sociedades humanas. Entre las dicotomías más famosas — todas conteniendo alguna referencia a los pares primitivo/civilizado o tradicional/modernopodemos enumerar: parentesco/territorio (Morgan); estatus/contrato (Maine); solidaridad mecánica/orgánica (Durkheim); comunidad/ sociedad (Tönnies); sociedades simples/complejas (Spencer); don/mercancía, o don(pág. 307)/contrato (Mauss); 
tradicional/racional ( Weber); holismo/individalismo (Dumont); historia fría/ caliente, pensamiento salvaje/domesticado (Lévi-Strauss).

Esas dicotomías evocan ciertos valores de la oposición naturaleza/cultura, con el primer término de cada una de ellas representando un estado más natural (en varios sentidos del término). Evocan también valores de la oposición individuo/ sociedad, aunque aquí la polaridad se invierte, pues los primeros términos denotan formas sociales donde prevalece el grupo como unidad básica, mientras que los segundos denotan una forma social donde el individuo gana preeminencia. Al final, estas repiten la división tradicional del trabajo teórico entre la antropología, que estudiaría las sociedades fundadas en el parentesco, con una economía del don, sin Estado, etc. Y la sociología, que se encargaría de las sociedades modernas, industriales y (originalmente) occidentales.

Las dicotomías arriba mencionadas puede ser interpretadas en términos de un dualismo ontológico que opone esencias sociales irreductibles, pero también como un contraste sobre todo heurístico, que exprime la predominancia de un polo sobre otro en el interior de cada tipo social. La tendencia reciente ha sido la de desconfiar ante formulaciones sugestivas de cualquier Gran Divisor, en particular aquellas que validan la imagen de "sociedad primitiva" establecida por los pensadores victorianos, y que había servido de modelo básico para la antropología desde entonces, argumentando que tal objeto teórico es una mera proyección invertida de la imagen, constituida a partir del siglo XVIII, de la sociedad burguesa moderna (Kuper 1988). Sea como fuere, la antropología no parece poder avanzar fácilmente sin tales dicotomías. Si estas arrastran consigo un pesado bagaje ideológico, no dejan por eso de mostrar una serie de diferencias de igual peso, entre la mayoría de las sociedades tradicionalmente estudiadas por la antropología y la sociedad capitalista moderna, diferencias cuyo rendimiento teórico puede ser atestado en el rescate de ciertos contrastes clásicos (Gregory 1982, Strathern 1988), o en las tentativas de relativizar y redefinir el Gran Divisor sin disolverlo completamente (Latour 1991).

La historia de la antropología registra diferentes maneras de concebir la relación entre los términos de estas dicotomías. Los evolucionistas la interpretaron como una sucesión histórica objetiva: la sociedad moderna sería una societas, la sociedad primitiva, antigua o tradicional una universitas. Tal solución, nótese, es dominada por la perspectiva de la societas, la cual aparece como la causa final de un movimiento progresivo envolviendo todas las sociedades, y por tanto como la verdad inmanente del mundo de la universitas. Desprovisto eventualmente de sus connotaciones teleológicas, ese modelo resuena en las tendencias teóricas que privilegian supuestos universales formales de acción (como la llamada escuela racional, por ejemplo) y que consideran las categorías sociológicas generadas por y para la sociedad moderna (como individuo, poder, interés, economía, política) aplicables a cualquier sociedad, viendo la oposición entre los tipos más de grado que de naturaleza.

La oposición alternativa, que enfatiza la diferencia cualitativa entre los términos, tiende a privilegiar la perspectiva de la universitas. Esta última sería la forma normal o "natural" de la sociedad, la societas moderna una singularidad histórica y/o una ilusión ideológica: el Occidente es un accidente... Aquí, la oposición entre los 
dos tipos de sociedad manifestaría sobre todo la diferencia entre dos concepciones sociocosmológicas globales y una de estas — la holista - revelaría la verdadera naturaleza de lo social. Tal idea, que lanza sus raíces inmediatas en la sociología de la religión durkheimiana y en el determinismo cultural de los boassianos, sufrió desarrollos bastante diferentes entre sí en las manos de autores como Dumont, Sahlins o Schneider. En la medida en que muchos antropólogos conciben su actividad como primordialmente la de emprender una crítica político-epistemológica de la razón sociológica occidental, esta posición ocupa un lugar central en la disciplina. La valorización de la universitas puede ser entrevista igual en aquellos autores que apuntan hacia una implicación mutua y necesaria entre visiones holistas e individualistas, rechazando ambas como etnocéntricas en nombre de las sociologías inmanentes a otras sociedades.

La "escuela" de la sociedad primitiva como objeto legó a la antropología una casi identidad entre su concepto de sociedad y el tema del parentesco. Las críticas de Maine y Durkheim al utilitarismo de Bentham y Spencer; el descubrimiento por Morgan de las terminologías clasificatorias amerindias, y su inserción en una teoría del parentesco como la unidad política original de la sociedad humana; las especulaciones de Mc Lenann y Bachofen sobre el matriarcado primordial, todo eso llevó a la antropología naciente a explorar una dimensión de la socialidad que la tradición contratista había negado en favor de la oposición inmediata entre el individuo y el Estado (pues la sociedad civil de los jusnaturalistas solo vino a significar plenamente una esfera distinta del Estado a partir de Marx). Al tomar el parentesco como lazo constitutivo de las unidades sociales primitivas, la antropología recuperó de cierta forma la concepción aristotélica de una continuidad natural entre la familia y la polis, aquella continuidad que, precisamente, había sido negada por los jusnaturalistas como fundamento legítimo de orden político. Aquí yace la inspiración profunda de la llamada teoría de la descendencia británica, producto de una fusión de los conceptos de estatus y de corporación de Maine con la solidaridad mecánica de Durkheim, que dominó la antropología británica en los años 40 y 50. Visto de este ángulo, se entiende mejor por qué para uno de los maestros de la teoría de la descendencia, el modelo concurrente de la alianza matrimonial de los estructuralistas franceses, es problemático: con la consanguineidad (fundadora de la descendencia) encerrando en sí el principio del estatus, la afinidad solo puede remitir al contrato, y por lo tanto a una dimensión secundaria del socius primitivo (Fortes 1969).

Es cierto que la teoría estructural del parentesco evoca algo del paradigma contratista, al concebir la prohibición del incesto como una intervención de la cultura en un espacio apartado indeterminado por la naturaleza (la elección del conyugue) y al definir el intercambio matrimonial en términos del sometimiento de las inclinaciones individuales a los intereses de orden colectivo. Aunque, aquí se trataría, más bien de un "contrato natural" establecido en el plano de la dinámica inconsciente de la vida social, que en su modalidad elemental liga grupos corporados de parentesco ( y no individuos) por lazos estatuarios perpetuos. En esta medida, descendencia y alianza remiten al modelo durkheimiano de "sociedad segmentaria" (Schneider 1965), hoy bajo fuerte sospecha crítica. 
Oponer las tradiciones antropológicas a partir de las antinomias y dicotomías arriba expuestas no pasa de ser una simplificación didáctica, pues la tensión entre los modelos hobbesiano y aristotélico —o malinowskiano y durkheimiano, para usar tótems más recientes (Kuper 1992) — es una verdad interna a las principales orientaciones teóricas, siendo así mejor hablar en preponderancias relativas. El esquema evolucionista, al proyectar en la diacronía la oposición entre el mundo colectivista primitivo, fundado en el parentesco grupal y en las relaciones normativas de estatus, al mundo individualista moderno, organizado en la base de la contigüidad local, del contrato moderno y de la libertad asociativa, ya mostraba un compromiso conceptual. Este sirvió de contraste crítico a casi toda la antropología social posterior, que se dedicó a mostrar la operación simultánea de ambas, las orientaciones en el interior de las sociedades "primitivas". En ese sentido, una solución muy común fue la división del campo social en dos aspectos complementarios, uno más social, el otro más individual, partición que se expresa en varios análisis famosos, empezando por el contraste trobriandés entre derecho materno y amor paterno (Malinowski), pasando por el papel del hermano de la madre en sociedades patrilineales (Radcliffe-Brown), y desembocando en oposiciones como descendencia versus filiación complementaria (Fortes), descendencia versus parentesco (Evans-Pritchard), estructura social versus organización social (Firth), estructura versus communitas (Turner). Una vez establecidas tales polaridades, el esfuerzo analítico de los antropólogos fue (algo paradójicamente) en buena parte dedicado a mediatizarlas, esto es, a determinar los mecanismos institucionales de articulación entre los lazos grupales y los lazos interpersonales, el orden doméstico de parentesco y el orden político de la sociedad global, el componente normativo obligatorio de las relaciones sociales y su componente optativo o estratégico.

En suma, se puede decir que la imagen de sociedad primitiva vigente en la fase clásica de la antropología social internalizó un contraste que había sido usado anteriormente para oponer globalmente sociedades o concepciones globales de la sociedad. Y por más que deba mucho de su inspiración a la tradición "aristotélica", hay un aspecto de la modernidad "hobbesiana" frente a la que la antropología no quedó inmune: se trata de la idea de que la sociedad, si es una condición natural, por consubstancial a la humanidad, no deja por eso de ser una condición problemática, esto es, algo que exige explicación, sino es que justificación. Esto se debe a su vez, a la idea (analizada, p. ej. en Strathern 1992a, b) de que la sociedad se constituye real o formalmente a partir de individuos asociales, que deben ser "socializados", esto es, obligados por la inculcación de representaciones normativas a comportarse de un modo determinado, y que resisten a esta imposición por una manipulación egoísta de las normas o por la regresión imaginaria a una libertad original. Tal idea se encuentra, con diferentes matices, tanto en Durkheim como en Freud, en Lévi-Strauss como en Fortes o Leach. El homo sapiens puede bien ser un "animal social", pero para la modernidad esta expresión sugiere un inquietante oxímoron que está en la raíz de la búsqueda incesante de la antropología, de soluciones que trasciendan las antinomias de ella derivadas. 


\section{Crítica y crisis}

La representación antropológica clásica de (una) sociedad precipitada por las tradiciones funcionalista y culturalista, es la de una mónada que exprime a su manera el universo humano: un pueblo étnicamente distinto, viviendo según instituciones específicas y poseyendo una cultura particular. La coincidencia ideal de los tres componentes constituiría una totalidad individual, dotada de organización y de finalidad internas. El énfasis funcionalista está en el aspecto total y sistemático, en el aspecto individual y expresivo.

Esta imagen ha sido cuestionada hace algún tiempo. En el plano teórico LéviStrauss $(1950,1958)$ insistió en que el estructuralismo no era un método de análisis de las sociedades globales, sugiriendo que una sociedad es un complejo contradictorio donde coexisten estructuras de diferentes órdenes, y que "el orden de los órdenes", o totalización inteligible de estas estructuras, es un problema antes ideológico que analítico. En el plano etnográfico, Leach (1954) demostró la inanidad de modelos epistemológicamente bien portados, que no toman en cuenta los contextos históricos y políticos de inscripción de las estructuras sociales.

Recientemente se ha observado que la noción de sociedad como totalidad autocontenida depende de categorías y de instituciones características de Occidente moderno, no podemos anhelar la universalidad antropológica del concepto, ni a la particularidad etnográfica de una concepción cultural. Se argumenta por ejemplo que la idea de una humanidad dividida en unidades étnicas discretas, social y culturalmente singulares, deriva de la ideología del Estado-nación, impuesta a los pueblos no occidentales por el colonialismo, ese gran inventor conceptual y práctico de "tribus" y "sociedades". Tal crítica (por ejemplo Wolf 1998) se ha traducido en un énfasis en la interdependencia de los sistemas sociales concretos (concebidos como superposiciones de redes sociales heterogéneas y abiertas), donde las relaciones constitutivas de configuraciones regionales más amplias determinan los procesos internos de las unidades locales - lo que disuelve la sociedad en sistemas cada vez más globales hasta el nivel planetario - y en un privilegio de conceptos de tipo procesual y pragmático en detrimento de conceptos de tipo estructural y normativo - lo que no infrecuentemente se resuelve en interacciones y representaciones atómicas-.

En su sentido general, la noción viene igualmente perdiendo terreno. La antropología contemporánea tiende a rechazar concepciones esencialistas o teleológicas de la sociedad como agencia trascendente a los individuos. A la sociedad como orden (instintiva o institucional) dotada de una objetividad de cosa, se prefieren nociones como socialidad, que expresaría mejor el proceso intersubjetivamente constituido de la vida social. Y realismo sociológico, así, ha dado lugar a una postura que extiende reflexivamente a la sociedad al mismo constructivismo que la sociología del conocimiento aplicó con éxito a la naturaleza (en particular a la naturaleza de las culturas del otro lado del Gran Divisor).

Se es posible definir una orientación predominante en la antropología contemporánea (Ortner 1984), esta consiste en el abandono de las concepciones estructurales de sociedad a favor de pragmáticas de la agencia social capaces de "promover una 
recuperación del sujeto sin caer en el subjetivismo" (Giddens 1979:44). Las distintas teorías de la "práctica", de la "acción comunicativa” o de la "estructuración” (Bordieu 1972; Sahlins 1981, Habermas 1984; Giddens 1984); la insatisfacción con la alternativa entre concepciones interactivo-naturalistas y regulativo-culturalistas de sociedad (Ingold 1986); la crítica unánime al paradigma "saussuriano" de la acción como actualización pasiva de un conjunto de reglas localizada en la conciencia colectiva o en el aparato mental de la especie - el retorno multiforme de abordajes fenomenológicos - son las señales de que la intencionalidad y la conciencia, antes descartadas como mero epifenómeno de estructuras que encerraban en sí la inteligibilidad y la eficacia de la sociedad (cuando no denunciadas como obstáculos epistemológicos a la determinación de estas estructuras) se vuelven ahora no apenas aquello que deber ser urgentemente explicado, si no la propia esencia (cuando no la verdadera explicación) de la socialidad. En suma: crisis de "estructura", retorno de "sujeto". Tal retorno puede ser teóricamente alertado, como en las propuestas que pretenden superar las antinomias del pensamiento social occidental, en particular aquella entre individuo y sociedad, que es la que está en juego en esa idea de una concepción no-voluntarista de la acción social. Pero esta puede también significar una retomada literal de varias figuras en buena hora rechazadas por los estructuralismos de las décadas recién pasadas: filosofía de la conciencia, celebración de la creatividad infinita del sujeto, retrascendentalización del individuo, etc. Recordando que cada teoría social ya venida a la luz creyó un día detentar la llave de la síntesis entre los polos de las antinomias de la razón sociológica occidental, apenas para ser más tarde acusada de favorecer escandalosamente uno de estos polos, resta ver si las neopragmáticas contemporáneas escaparán de ser un mero momento de la oscilación perenne entre nominalismo subjetivista de las societas y el realismo objetivista de las universitas.

La crítica contemporánea atiende la noción de sociedad por todos los lados: la sociedad primitiva como tipo real; la sociedad como objeto empíricamente delimitado; la sociedad como soporte objetivo de las representaciones colectivas, entidad dotada de coherencia estructural y de finalidad funcional. Tal crisis conceptual deriva, en primer lugar, de una crisis histórica. El fin del colonialismo político formal y la aceleración de los procesos de mundialización de los flujos económicos y culturales tornaron más evidente el carácter desde siempre ideológico y artificial de algunas de las ideas en cuestión: la mónada primitiva no era primitiva, y nunca fue monádica.

Esta crisis histórica refleja también un cambio en la percepción social occidental, esto es, una crisis cultural. El objeto-idea de la antropología, la "sociedad primitiva”, se disolvió menos por la (bastante relativa) globalización objetiva de los mundos primitivos locales, o por el (algo dudoso) progreso de las luces antropológicas, que por el quiebre de la noción de "sociedad moderna" que le sirvió de contra-modelo. Crece la convicción de que el Occidente abandonó su periodo moderno, fundado en la separación absoluta entre el dominio de los hechos y el dominio de los valoresseparación que permitía atribuir, por un lado, trascendencia objetiva al mundo natural e inmanencia subjetiva al mundo social, y por otro lado, instrumentalidad pasiva a los objetos y agencia coercitiva a los valores. Resta ver si ingresamos (y este "nosotros" incluye a todas las sociedades del planeta) a una fase posmoderna donde no funciona 
más tal separación, o si, al contrario de lo que supone la cosmología del Gran Divisor que volvió posible la antropología, jamás fuimos modernos, excepto en la imaginación de algunos ideólogos (Latour 1991). Sabemos, mientras tanto, y esto es una lección de la propia antropología, que concepciones imaginarias (aunque todas lo sean) producen efector reales (y todos lo son). Si este es el caso, entonces continuamos en la búsqueda de conceptos capaces de iluminar las diferencias entra las sociedades, única vía abierta a la antropología para proponerse eficazmente la condición social de un punto de vista verdaderamente universal, o mejor, "multiversal", esto es, un punto de vista capaz de generar y desarrollar la diferencia.

\section{BIBLIOGRAFÍA}

BOBBIO, Norberto

1993 Thomas Hobbes and the Natural Law tradition (trad. D. Gobetti). Chicago: Univ. of Chicago Press.

DUMONT, Louis

1965 [1983] "La catégorie politique et l'État à partir do XIII eme siècle", in: Essais sur l'individualisme: una perspective anthropologique sur l'idéologie moderne. Paris: Mouton, pp. 117-41.

EARLE, Timothy

1994 "Political domination and social evolution", in T. Ingold (org.). Companion encyclopedia of anthropology: humanity, culture and social life. Londres: Routledge, pp. 94-61.

FIRTH, Raymond

1951 [1971] Elements of social organization. Londres: Tavistock.

FORTES, Meyer

1969 Kinship and the social order: the legacy of Lewis Henry Morgan. Londres:

Routledge and Kegan Paul.

1983 Rules and the emergence of society. Londres: Royal Anthroplogical Institute of Grat Britain and Ireland.

GIDDENS, Anthony

1979 Central problems in social theory: action, structure and contradiction in social analysis. Berckeley: Univ. of California Press.

1984 The constitution of society: outline of the theory of structuration. Cambrige: Polity Press.

GREGORY, Cris

1982 Gifts and commodities. Londres: Academic Press.

INGOLD, Tim

1986 Evolution and social life. Cambridge: Cambridge Univ. Press

1994 "Humanity and animality", in T. Ingold (org.). Companion encyclopedia of anthropology: humanity, culture and social life. Londres: Routledge, pp. 14-32 
KUPER, Adam

1988 The invention of primitive society: transformations of an illusion. New York: Routledge.

1992 “Introduction”, en A. Kuper (org.) Conceptualizing society. Londres: Routledge and Kegan Paul, pp. 1-14.

LATOUR, Bruno

1991 Nous n'avons jamais été moderns. Paris: La Décoverture.

LEACH, Edmund

1954 [1965]. Political systems of Highland Burma: a study ok Kachin social structure. Boston: Beacon.

LÉVI-STRAUSS, Claude

1950 "Introduction à l'oeuvre de Marcel Mauss" in M. Mauss, Sociologie et anthropologie. Paris: PUF.

1958 Anthropologie structurale. Paris: Plon.

1967 a Les structures élementaires de la parenté (2a edición/1a ed.: 1949) Paris: Mouton.

ORTNER, Sherry

1984 "Theory in anthropology since the sixties". Comparative Studies of Society and History, 26, pp. 126-66.

SAHLINS, Marshall

1972 Stone Age economics. New York: Aldine

SCHNEIDER, David

1965 "Some muddles in he models: or, how the system really works", in: M. Banton (org.). The relevance of models for social anthropology. ASA Monographs I. Londres: Tavistock, pp. 25-85.

STOCKING JR, George

1987 Victorian anthropology. New York: McGraw-Hill.

STRATHERN, Marilyn

1988 The gender of the gift: problems with women and problems with society in Melanesia. Berckeley: Univ. of California Press.

1992a After nature: English Kinship in the late twentieth century. Cambrigde: Cambridge Univ. Press

1992b Reproducing the future: anthropology, Kinship, and the new reproductive technologies. New York: Routledge.

VERDON, Michel

1991 Contre la culture: fondement d'une anthropolgie sociale opérationnelle. Paris: Archives Contemporaines.

WOLF, Eric

1988 "Inventing society". American Ethnologist, z5 (4), pp. 752-61 